\title{
SELF-INCOMPATIBILITY IN LOLIUM PERENNE L.
}

\author{
W. SPOOR* \\ Department of Botany, The University, Whiteknights, Reading RG6 2AS \\ Received 1.vi.76
}

\section{SUMmary}

Self-incompatibility in Lolium perenne is shown to be controlled by a complicated multifactorial system with at least three loci. Pollen control is gametophytic. The growth of incompatible pollen tubes is usually inhibited on the stigmatic surface. The incompatibility mechanism does not appear to be particularly strong, since partial self-compatibility is found in some plants.

\section{INTRODUCTION}

Self-incompatibility systems are found in many cultivated plants. Selection and the breeding techniques employed must be adjusted to the characteristics of the self-incompatibility in a species. Previously, the use of selfincompatibility as a means of crossing without emasculation in the production of commercial $\mathrm{F}_{1}$ hybrid seed, has been limited to a few species, most notably in the Cruciferae (Johnson, 1966). More recently it has been suggested that self-incompatibility might be manipulated for the production of $\mathrm{F}_{1}$ hybrid seed in forage grasses (England, 1974). However, this scheme depends for its success on the elucidation of the self-incompatibility system in a particular grass species.

In the Gramineae several workers (Lundquist, 1954, 1955, 1956, 1961a, 1962, 1969; Hayman, 1956; Murray, 1974) have demonstrated a gametophytic control of self-incompatibility, involving two multi-allelic genes. Furthermore, the systems described by the above authors have certain common characteristics. Firstly, the incompatibility reaction is caused when the alleles at both loci in the pollen are matched in the style, and secondly, interaction between the two loci has not been demonstrated, and thus it would appear that the two loci have a physiological unity (Lundquist, 1956).

The incompatibility system operating in Lolium perenne has been examined by several workers. For example, Weimarck (1968) claimed to show that a 2-locus, gametophytic control of incompatibility existed in this species. The experimental results presented by Weimarck in support of this view could equally well be interpreted in terms of a one-locus gametophytic incompatibility system. Further work by Hayward and Wright (1971) using empty pollen grains on the stigma 24 hours after pollination as an indication of compatibility, concluded that no precise one- or two-locus system was operative in this species.

Thus, in order to examine more completely the incompatibility system of $L$. perenne, a diallel cross was made, using an $\mathrm{F}_{1}$ family. As a means of avoiding the difficulties experienced by Hayward and Wright (1971) pollentube growth through the stigmatic tissue was examined to determine compatibility or incompatibility.

* Present address: East of Scotland College of Agriculture, West Mains Road, Edinburgh EH9 3JG. 


\section{Materials and methods}

An $F_{1}$ progeny was produced by controlled cross-pollination of two completely self-incompatible $L$. perenne plants from different populations. The mating behaviour of the $F_{1}$ progeny was then analysed in a $28 \times 28$ diallel (fig. 1), using the petri dish technique as described by Lundquist $(1961 b)$. Pollen tubes were examined 6 hours after pollination by means of the callose fluorochrome reaction (Lalouette, 1967).

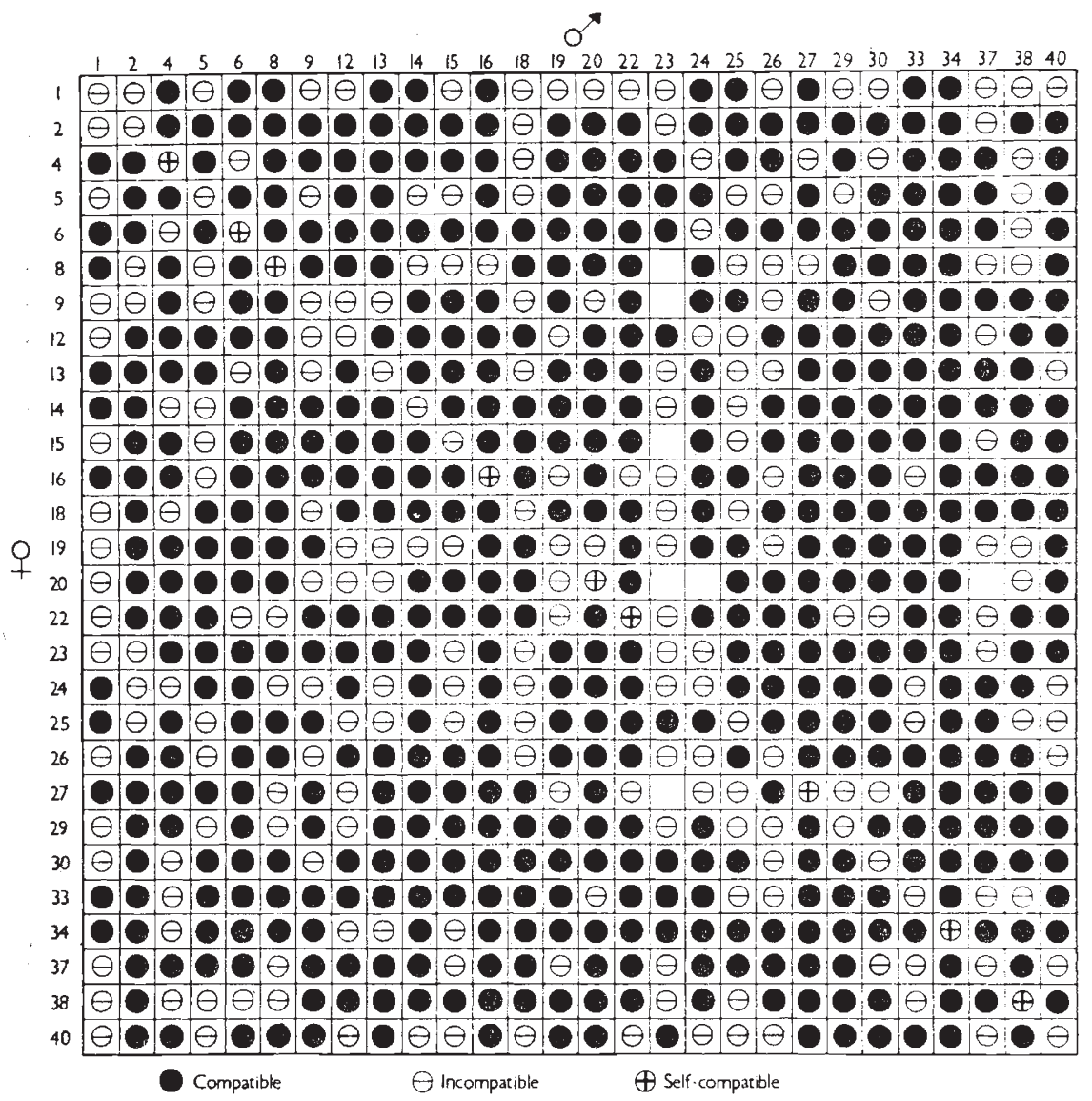

Fig. 1.-Results of crosses among $28 \mathrm{~F}_{1}$ L. perenne plants.

\section{Results}

The diallel cross (fig. 1) shows firstly that, unlike the parent plants, some of the $F_{1}$ generation are self-compatible ( 9 out of $28 F_{1}$ plants). In many of these self-compatible plants there were both successful pollen tubes and pollen tubes which burst growing some way down the style. The quantity of seed from those plants exhibiting self-compatibility was small.

In compatible crosses differential behaviour of the pollen was frequently observed, indicating gametophytic control of the pollen specificity. A total 
of 83 reciprocal differences in pollen germination were found, i.e. cases in which the cross between two plants is compatible in only one direction. The occurrence of reciprocal differences is characteristic of the sporophytic control of incompatibility.

The $28 \mathrm{~F}_{1}$ plants cannot be arranged into mating groups which are both intercompatible and intra-incompatible. For example plants, 1, 5, 9, 26 form an intra-incompatible group (fig. 2). However, the differing reactions

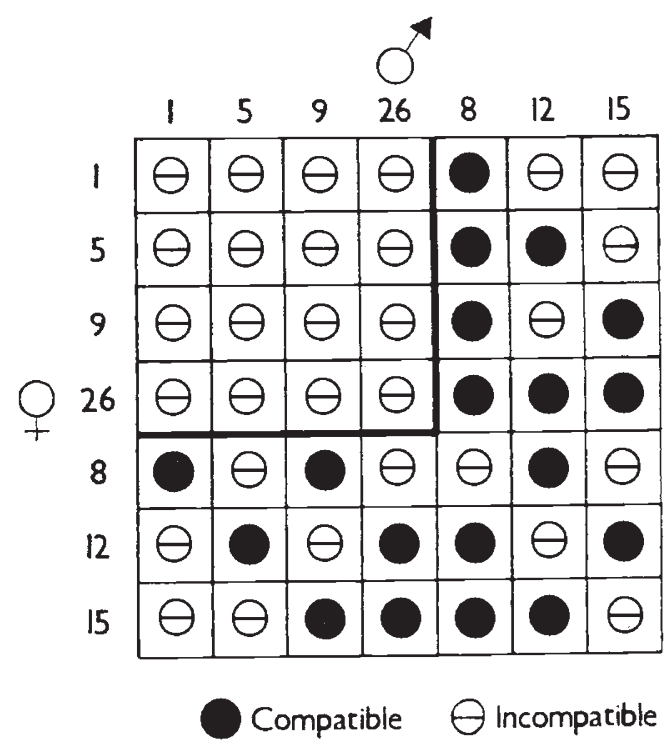

FIG. 2.-Results of the crosses among seven plants from the $F_{1} L$. perenne progeny, arranged to show an intra-incompatible group.

of these four plants with other $\mathrm{F}_{1}$ plants of the diallel e.g. 8, 12, 15 indicate that they do not in fact belong to one and the same mating group. Thus, within this diallel cross, each of the $28 \mathrm{~F}_{\mathbf{1}}$ plants is unique.

\section{Discussion}

The results of the diallel cross show 28 different mating types, with a complicated pattern of cross-compatibility, cross-incompatibility and reciprocal differences. Variation in individual pollen-tube penetration in certain crosses indicates gametophytic control of pollen behaviour. If the control were sporophytic all the pollen in a cross would have reacted in the same way. These results cannot therefore be satisfactorily explained in terms of any theory so far postulated in the Gramineae or any other family.

It has been proposed by Lundquist $(1954,1965)$ and Hayman (1956) that incompatibility in the Gramineae is controlled by two loci, $S$ and $Z$, both with multiple alleles, gametophytic control of pollen behaviour and individual action of alleles in the style. According to this hypothesis, an $\mathrm{F}_{1}$ progeny, from two unrelated plants, i.e. with no alleles in common, can show a maximum of 16 different mating types. Analysis of this $\mathrm{F}_{1}$ progeny has revealed 28 mating types. If a three-locus control of incompatibility 
was postulated a maximum of 64 different mating types would be expected. Thus these results can be interpreted in terms of at least three loci controlling incompatibility. The high number of reciprocal differences would be anticipated if the two parent plants have two or three alleles in common.

In the two-locus gametophytic incompatibility system, crosses between different genotypes i.e. mating types, in an $\mathrm{F}_{1}$ progeny, will either be crosscompatible in both directions or will show reciprocal differences (if parent plants share common alleles). Extending this to a three-locus control of incompatibility, similar results can be expected between the different mating types of an $\mathrm{F}_{1}$ progeny. In either case, complete cross-incompatibility would not occur between the different mating types. However, fig. 2 shows four plants, with different mating types, which are completely crossincompatible and many other examples can be found in the diallel. Since this is a diagnostic feature of a sporophytic system, it presents a paradox.

Lundquist (1954) has found that in the two-locus gametophytic system, both alleles in the pollen must be matched in the style to cause incompatibility, and cases of two-way cross-incompatibility between mating types do not occur. Pandey (1957) using Physalis ixocarpa has demonstrated a twolocus gametophytic incompatibility system in which one or both the alleles in the pollen must be matched in the style to cause incompatibility. Furthermore in Physalis, two-way cross-incompatibility does occur, between mating types. Thus the cross-incompatibility found between the different mating types in Lolium perenne may indicate that only one or two alleles in the pollen need to be matched in the style to cause incompatibility. Alternatively, epistasis between the alleles at the different loci, such that some alleles are more effective than others in inhibiting pollen tube growth, would have the same effect.

The self-incompatibility mechanism in L. perenne appears to be complex, and not particularly strong since 9 out of $28 \mathrm{~F}_{1}$ plants showed some selfcompatibility. Variation in the efficiency of the self-incompatibility mechanism has also been noted by several workers (Breese, 1966; Foster and Wright, 1970). This may be an advantage in those plants with genotypes which are successful in a particular environment. However, considerable inbreeding depression usually occurs and self-fertilised lines rarely survive beyond the 2nd or 3rd generation (Breese, 1966).

The genetic basis of self-incompatibility is usually similar in closely related groups although exceptions to this rule have been found, for example in the Solanaceae and Boraginaceae (Pandey, 1957, 1962; Crowe, 1971). The results obtained in the diallel cross of an $\mathrm{F}_{1}$ L. perenne progeny indicate a multifactorial control of incompatibility, with at least three loci but possibly more. Thus it would appear that the two-locus control of self-incompatibility, commonly found in the Gramineae, is not universal in the family.

Acknowledgments.-I would like to thank Dr Leslie K. Crowe for her help and encouragement throughout the course of this work. A postgraduate studentship from the Science Research Council is also gratefully acknowledged.

\section{REFERENCES}

BREESE, E. L. 1966. Reproductive Biology and Taxonomy of Vascular Plants, ed J. G. Hawkes. Pergamon Press.

CROWE, L. K. 1971. The polygenic control of outbreeding in Borago officinalis. Heredity, 27, 111-118. 
ENGLAND, F. J. W. 1974. The use of incompatibility for the production of $F_{1}$ hybrids in forage grasses. Heredity, 32, 183-188.

FOSTER, C. A., AND WRIGHT, C. E. 1970. Variation in the expression of self-fertility in Lolium perenne. Euphytica, 19, 61-70.

haYMAN, D. L. 1956. The genetical control of incompatibility in Phalaris coerulescens Desf. Aust. F. Biol. Sci., 9, 321-331.

HAYWARD, M. D., AND WRIGHT, A. J. 1971. The genetic control of incompatibility in Lolium perenne. Genetica, 42, 414-421.

JoHNSON, A. G. 1966. Inbreeding and the production of commercial $F_{1}$ hybrid seed of brussels sprouts. Euphytica, 15, 68-79.

LALOUETTE, J. A. 1967. Growth of grass pollen tubes exhibited by callose fluorochrome reaction. Grana Palynologica, 7, 601-603.

LUNDQUTST, A. 1954. Studies on self-sterility in rye, Secale cereale L. Hereditas, 40, 278-294. LUNDQUIST, A. 1955. Genetics of self-incompatibility in Festuca pratensis. Hereditas, 41, 518-520.

LUNDQUIST, A. 1956. Self-incompatibility in Rye. I. Genetic control in the diploid. Hereditas, 42, 293-348.

LUNDQUIST, A. 1961a. Self-incompatibility in Festuca pratensis Huds. Hereditas, 47, 542562.

LUNDQUIST, A. 1961b. A rapid method for the analysis of incompatibility in grasses. Hereditas, 47, 705-707.

LUNDQUisT, A. 1962. Self-incompatibility in diploid Hordeum bulbosum L. Hereditas, 48, 138-152.

LUnDQuist, A. 1965. Genetics of incompatibility. Genetics Today (Proc. XI Int. Congr. Genetics, The Hague), 3, 637-647.

LUNDQUisT, A. 1969. Self-incompatibility in Dactylis glomerata L. Hereditas, 61, 353-360.

MURRAY, B. G. 1974. Breeding systems and floral biology in the genus Briza. Heredity, 33, 285-292.

PANDEY, K. K. 1957. Genetics of self-incompatibility in Physalis ixocarpa Brot.-A new system. Am. F. Bot., 44, 879-887.

PANDEY, K. K. 1962. Genetics of incompatibility behaviour in the Mexican Solanum species. S. pinnatisectum 2. Vererblehre, 93, 378-388.

WEIMARCK, A. 1968. Self-incompatibility in the Gramineae. Hereditas, 60, 157-166. 